\title{
A encenação do corpo
}

\author{
Yanet Aguilera
}




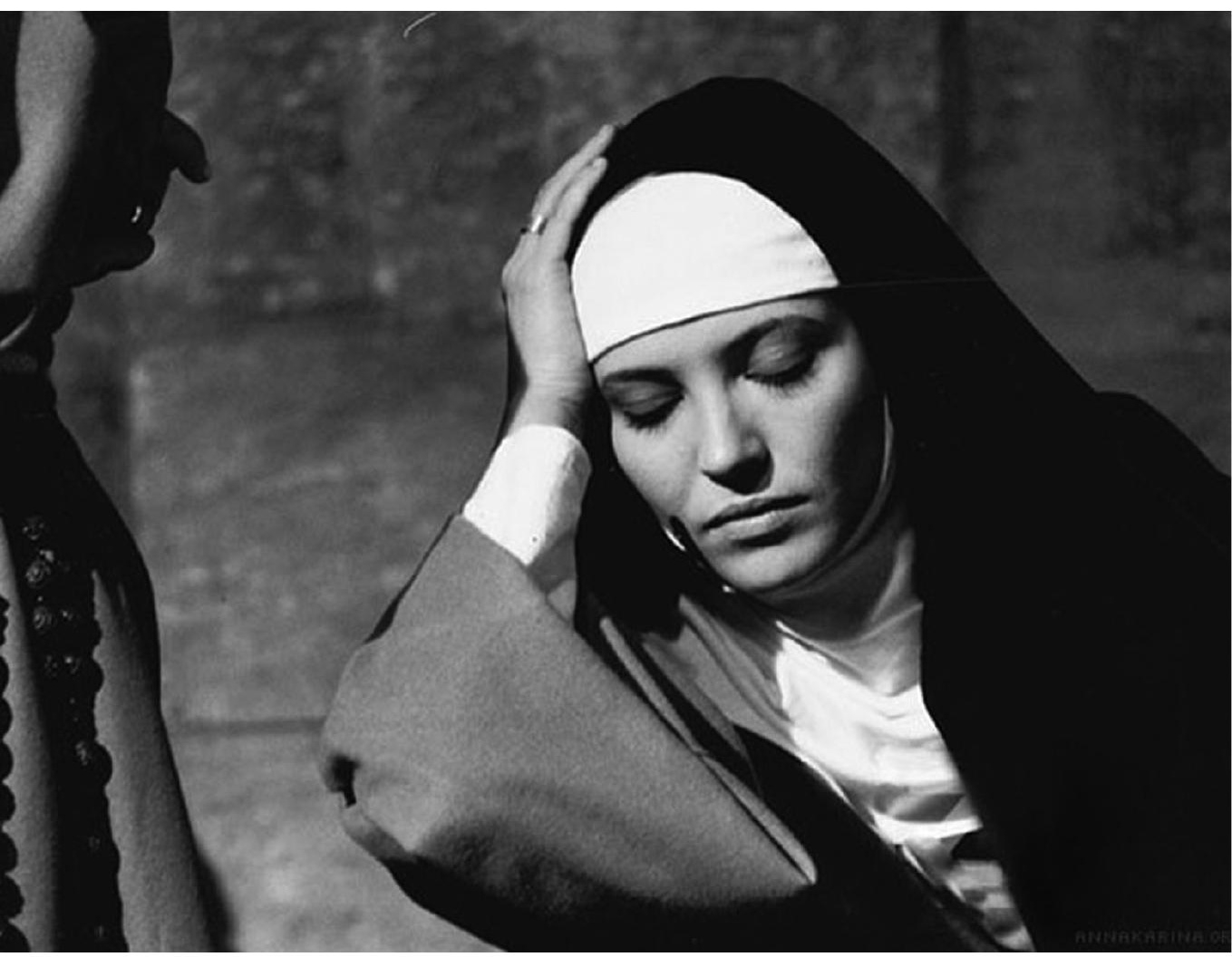


Jacques Rivette fez A Religiosa em 1966, quando ainda era diretor dos Cahiers du Cinéma. Como um dos integrantes mais proeminentes da Nouvelle Vague, ajudou a mudar a maneira de ver, entender e fazer filmes, o que colocou o cinema no horizonte do estudo das humanidades.

A cinefilia francesa praticamente cria os cineastas que nos acostumamos a cultuar como autores. Alfred Hitchcock, por exemplo, não teria a importância que tem hoje sem os integrantes da Nouvelle Vague. Pode-se dizer até, com certo exagero, que o cineasta inglês é uma invenção dos críticos dos Cahiers. O que teria ele de especial? Hitchcock é erigido como um dos maiores no panteão de autores porque seus filmes podem ser vistos como uma reflexão sobre o cinema. De modo que o distanciamento reflexivo é um dos elementos principais que constitui a experiência cinéfila: saber que fundamenta quase todas as críticas daqueles que serão os futuros cineastas da Nouvelle Vague.

O fato de o filme A Religiosa ser uma adaptação do romance homônimo de Diderot, que é visto como uma sátira patética, levanta a seguinte questão: como Rivette, que vem dessa escola, por assim dizer, do distanciamento, escolhe um romance cuja referência, para a maioria dos estudiosos da obra de Diderot, é a encenação teatral, que se desenvolve pela intensificação patética de quadros-cenas?

Surpreendentemente, em nenhum momento Rivette busca a ruptura da linearidade narrativa ou dos nexos causais por meio de associações inusitadas, não faz nenhuma colagem modernista e nem destrói propositalmente uma suposta sintaxe cinematográfica, como Godard faz, por exemplo. Tampouco se interessa pelo fato de ser um romance inacabado, imperfeito, construído por meio de uma "técnica bastarda", entre o romance de memória e o diário íntimo, como afirma Franklin de Mattos, no artigo sobre A Religiosa, em A cadeia secreta (Mattos, 2005). Como leitor da segunda metade do século XX, que menospreza a verossimilhança, exigência estética aristotélica encampada pelo século XVIII e 
XIX, Rivette poderia ter destacado as associações inesperadas que se lhe apresentavam por meio da dita "técnica bastarda". Não o faz. Tampouco usa o adendo do romance, ou seja, as cartas entre o bando de filósofos - Diderot, Grimm, etc. - e o marquês de Croismare. Teria escapado a Rivette um personagem que parece ter sido feito de encomenda para desconstruir o tão famigerado ilusionismo das artes? O nobre encarna o tradicional leitor iludido, pois aparentemente acredita estar trocando cartas com a verdadeira religiosa e se compadece pela sua sorte, oferecendo-lhe abrigo. É célebre o episódio em que os comparsas de Diderot, com saudades do marquês, que tinha se retirado para a província, tentaram enganá-lo com esta história melodramática a fim de fazê-lo voltar a Paris. O cineasta nem menciona a revelação do engano, exposto numa carta de Grimm e que faz parte das edições do romance desde o século XVIII.

Por outro lado, Rivettepermanece o mais fiel possível ao romance, além de destacar, nos diálogos, as frases mais expressivas. Entretanto, como é um filme relativamente longo, com mais de duas horas, e como está constituído por longos planos sequências, a intensidade do drama se desfaz. Percebe-se ainda um esforço para evitar a intensidade patética da trágica história de Suzanne Simonin. Apesar das imagens da protagonista jogando-se no chão e perambulando perturbada pelos corredores do convento, Rivette marca inexoravelmente uma distância com a câmera, neutralizando a intensidade dessas cenas. A preponderância do plano médio distancia ainda mais porque quase exclui os closes, que permitiriam ao espectador viver o sofrimento da protagonista por meio da expressão facial ou do gesto monumentalizado. Evita também o plano geral que deixaria visível a orquestração da cena, no sentido teatral do termo, retirando a expressividade da interação entre ambiente e personagem. Em consequência, se subtraem a nosso olhar os pés dessas personagens. Depois de Boticelli, sabemos o que valem, por assim dizer, pés bem colocados. Portanto, a estruturação do quadro diminui sensivelmente a 
intensidade do drama. Assim, a primeira vista, o filme parece uma adaptação menor, pois o cineasta se manteria fiel à letra, mas lhe escaparia o espírito do romance.

Nem desconstrução distanciada nem intensidade dramática, a opção da adaptação é mais sutil e complexa.Sabemos que a autorreflexão cinematográfica desfaz a ilusão, à qual se supõe que o público do cinema está inexoravelmente submetido. Todo espectador, na teoria do dispositivo ideológico cinematográfico, é um ingênuo Marquês de Croismare. Porém, Rivette deixa intacta a dita estrutura ilusionista do romance. Pelo menos, não rompe com os elementos identificados como responsáveis pelo engano. Ele não parece interessado em opor ciência a inconsciência ou o intelecto à emoção patética.

Como Diderot, que sabe muito bem o valor da intensidade imagética de Greuze e de Richardson, Rivette também conhece o forte efeito que causa a cena visual - a teatral, a da pintura e a do cinema.Está ciente que a empatia provocada por uma encenação visual não se anula simplesmente ao prevenir o espectador desavisado dos artifícios que são necessários para provocar a emoção do público.Assim, presumo que, ao adaptar A Religiosa, Rivette quer estabelecer outro tipo de diálogo com Diderot, que não fica circunscrito a um distanciamento que se limite a questionar a estrutura narrativa ou temática do romance.

Fora da dicotomia tradicional que coloca a crítica entre a assunção da ilusão e asua ruptura, o filme busca, na construção de seus planos, uma relação fechada e sinuosa com o quadro ou tableau proposto pelo romance. Logo após um pequeno prólogo', vemos um plano em que os parentes de Suzanne e os amigos da família acompanham o ritual em que ela vai professar. Grades de

1 Nesses momentos iniciais, aos letreiros explicativos segue-se o retrato de Diderot pintado por Louis Michel Van Loo, em 1770, e que reaparecerá no final da sequência, depois de uma série de imagens das freiras e da vida monástica. Essas gravuras e retratos serão comentados adiante. 
ferro separam a sociedade laica do espaço consagrado à religião. Desesperada, a protagonista implora por sua liberdade. Em segui$\mathrm{da}$, as freiras retiram a postulante e fecham cortinas vermelhas de veludo, que subtraem a cena de coação à qual Suzanne é submetida. Estas imagens fazem parte de iconografias bastante conhecidas. Embora a última remeta à cena teatral, sugestivamente os panos que se fecham indicam o fim da encenação, não seu começo. A outra remete à prisão, aludindo a uma estética do confinamento, como Luiz Roberto Takayama apontou em sua análise do filme. As grades reaparecem em inúmeras cenas dividindo dois ambientes. Embora a clausura seja a de Suzanne, os parentes, amigos, o padre confessor e o advogado são colocados em recintos tão claustrofóbicos quanto aqueles que a protagonista ocupa. Não há um fora e um dentro a distinguir. Assim, as grades não estão ali para dividir os espaços, mas para marcar um instrumento material constante que, a meu ver, cumpre duas funções: fragmentam o quadro e, principalmente, o corpo das personagens. Consequentemente, as grades e as cortinas obstruem a visibilidade da unidade cênica tão necessária à representação patética.

Além disso, a atuação dos atores, em grande parte do filme, é de uma contenção que raia a imobilidade. Embora Ana Karina, que vive a religiosa, em vários momentos se dilacere, permanece quase sempre meio de costas para o espectador, nem mesmo configurando um perfil enigmático de si. Então, por que a insistência em exibir sua agonia, ao mesmo tempo que vemos, de fato, tão pouco dela? Como já foi dito, Rivette não recorta nem focaliza por meio do close uma opção considerada especificamente cinematográfica e muito propícia para a encenação melodramática. Essa escolha torna o filme aparentemente gélido, ainda mais pela paleta de cores frias que domina os enquadramentos.

Talvez devamos tentar entender esta opção como um paradoxo visual - se mostra e se oculta ao mesmo tempo -, que também tem a função de rebaixar a intensidade da cena dramática. O que se produz neste jogo de exibir e obstruir a visão do destino trágico 
da religiosa? Insistentemente se visualizam celas fechadas, longos corredores mergulhados na penumbra e ainda grades que fragmentam os corpos. Estes espaços não são apenas cenários para um drama pessoal, mas elementos que parecem oprimir cada vez mais o corpo de Suzanne, principalmente porque se debate desesperadamente sem poder se safar desses muros que a esmagam.

Como diz Adriano Aprá (1992, p. 145-150)2, os conventos são labirintos. Suzanne é filmada como uma mosca presa numa armadilha da qual tenta desesperadamente se safar. Esta imagem é reforçada pelo jogo cromático do filme. As paredes e os hábitos são cinzas, fazem desaparecer o corpo, indissoluvelmente preso aos muros que o comprimem. Praticamente, há uma luta entre o corpo e as paredes do convento, entendendo-se, assim, a insistência em ocultar o rosto da religiosa. Como se deixam em luz baixa os aspectos patéticos da historia e se intensifica visualmente a relação entre o corpo da protagonista e as paredes, pode-se dizer que se substitui o drama teatral, no sentido literário, por um teatro do corpo, no sentido visual. Isto nos leva a considerar a história de Suzanne Simonin a partir das imagens, o que implica que os planos não são mera ilustração da narrativa. Ao contrário, é o texto que se deve depreender deles.

Esta opção não é estranha ao próprio romance, porém, está nas bordas ou nas entrelinhas da história dramática de Suzanne. Os nomes que Diderot dá às superioras, e que Rivette mantém, são reveladores nesse sentido. Por exemplo, a irmã nobre e boa com Suzanne chama-se De Monie. Como o nome sugere, é o próprio demônio. A mais ardilosa e fátua brinca irresponsavelmente com as máscaras teatrais da sensibilidade e dos sentimentos. É ela que perde Suzanne ao convencê-la a professar. Como uma aranha, sub-repticiamente, a prende em sua teia infernal.

2 Traduzido do francês por Bruno Andrade. O texto foi originalmente publicado como "Il cinema di Jacques Rivette", em Quadernoinformativen. 62, Mostra Internazionale Del Nuovo Cinema, Pesaro, 1974. 
A irmã Cristina, o feminino de Cristo, leva até as última consequências o proposto na doutrina cristã. De maneira direta e brutal, esta freira mostra o que é supliciado no claustro: o corpo. $\mathrm{O}$ sadismo da superiora não é mera perversão, é efeito consequente da vocação religiosa. As histórias de autossuplícios dos santos estão aí para atestá-lo. O verbo que se fez carne, mas carne antes de tudo macerada e torturada. Na figuração da mulher cristã, Maria Madalena, que sempre carrega o instrumento do flagelo, é fundamental. Este pequeno e feroz chicote tortura e disciplina o corpo que, apesar da vocação religiosa, sempre se rebela.

O segundo convento para o qual Suzanne é mandada também deixa claro que o que está em jogo é o corpo mortificado, agora, porém, remetido à impossibilidade de realização de seus instintos naturais. O correlato narrativo deste episódio são os livros pornográficos. Assim como as imagens de boudoir são a cena proibida, apenas vista pelo buraco da fechadura ou lida clandestinamente, a superiora deste convento não tem nome. No espaço do teatro do corpo, a cena pornográfica não pode ser vista nem nomeada. O figurino da superiora, que é destacado no romance, se torna central no filme. Ela usa espartilho, assim como as damas da sociedade de sua época. Geralmente a roupa íntima é lida como um sinal profano que marcaria a frivolidade desse convento. Entretanto, esta leitura assume o julgamento moral do ponto de vista religioso. A cincha (um nome menos glamoroso) é também um instrumento de tortura que as mulheres aprenderam a suportar. $\mathrm{O}$ corpo feminino da vida mundana é idealizado, obtido por meio de seu tormento e, portanto, seu sofrimento sublimado é equivalente à brutalidade do corpo negado das freiras.

Esses corpos torturados do filme não reiterariam o olhar voyeur do cinema, centrado no desvendamento da vida íntima das pessoas? Iconograficamente, pode-se pensar como antídotos à abordagem obscena os interiores burgueses que eram tão caros a Diderot, o esteta encantado com as cenas da vida doméstica de Greuze, lugar das afeições e dos sentimentos. Entretanto, no 
romance e na adaptação cinematográfica de A Religiosa, esta idealização da intimidade burguesa desaparece. Afinal, são os pais e o mundo que obrigam Suzanne a professar. Há, portanto, uma indistinção entre um dentro e um fora, como já havíamos mencionado. Se o claustro é a prisão, o mundo de fora não é o espaço da liberdade. Aliás, o primeiro é consequência do segundo.

O figurino volta a ser fundamental para entender melhor esta questão, pois escancara que a separação moral dos espaços da vida em família e da vida pública não existe. O século burguês que valoriza a representação da cena íntima criou uma indumentária condizente com a exposição do interior: o robe de chambre, importante na iconografia do século XVIII. Van Loo pintou Diderot duas vezes no desalinho elegante e íntimo. O filme começa com um destes retratos, como já mencionei. A outra tela do filósofo, de 1767 , é mais conhecida porque foi comentada negativamente num dos Salões. Diderot não gostou da forma idealizada do retrato. Em que consiste essa idealização? O azul cobalto da roupa íntima sobreposto ao branco da camisa torna ainda mais suave e atraente o rosto rosado de Diderot. Esses estratagemas de luz e cor eram muito usados para apresentar uma versão mais favorável dos retratos das damas aristocratas ou das burguesas endinheiradas. Obviamente que esta opção retirava a dignitas da figuração do filósofo. Parece que o pintor entendeu a crítica, pois o segundo retrato, de 1770, escolhido por Rivette, tem uma ar mais sóbrio, resultado do robe mais escuro e de um olhar mais penetrante, devido às sobrancelhas e às íris dos olhos marcadamente pretas, além de uma calvície mais pronunciada. A lição que Van Loo parece ter aprendido é que a representação da intimidade sempre corre o risco de se tornar um pouco coquete, mesmo que se trate de uma figura masculina.

O robe de chambre feminino, por sua vez, não escapa a essa conotação, sempre teve um significado sexualizado, objetualizando o corpo da mulher. Entretanto, Rivette se desvia magistralmente dessa direção, ao mostrar a roupa íntima no desalinho corporal 
e não remetida ao desejo que a vestimenta desperta, mas à paixão não usufruída. A superiora, ensandecida por não poder fazer de Suzanne sua amante como fizera com as outras pupilas, vaga em robe de chambre, perdida pelos corredores escuros. Esta mulher, que se negou a sacrificar o gozo corporal em nome da vaga promessa de uma vida plena fora do mundo, acaba se arrependendo no final. A contrição aparece já no desvario e no vagar desolado da superiora. Porém, como acaba duplicando a errância de Suzanne quando estava sendo mortificada pela freira Cristina, a conotação moral acaba perdendo em importância. A não assunção do ponto de vista do julgamento religioso fica evidente pelo fato de a intensidade do extravio mental da superiora se manifestar não apenas em seu desalinho, mas no som estridente do saltinho que marca o sapatinho mundano, que Rivette nos obriga a escutar. Ao apresentar este forte fetiche sexual, o som reafirma a cena pornográfica, marcando mais uma vez o que está por trás do drama patético, carregado pela moralidade cristã. Aliás, o som é bastante utilizado para ironizar a vida religiosa - quando Suzanne está sendo cortejada pela superiora, ouve-se o arrulho de pombas etc.

O jogo entre a encenação patética e a pornográfica é ainda reduplicado no espaço externo. Rivette nos faz assistir às cenas dos exteriores, nas quais deveríamos sentir os ares da liberdade, como uma imagem especular do dentro. Na festa no prostíbulo fica evidente que as roupas femininas remetem a uma espécie de máscara que as mulheres devem apresentar para poder circular dignamente no mundo, mesmo nos salões do bordel. O suicídio de Suzanne mostra a impossibilidade do homem moral sobreviver e as tentativas vãs de sair do teatro, e de suas máscaras, para a vida. No espaço mundano, o jogo das máscaras marcará o triunfo da teatralidade, segundo Aprá (1992).

A surpresa é que este final não é o do romance, configurando assim, uma espécie de traição, visto que parecia ter se optado por uma adaptação "fiel" do livro. No momento em que a religiosa escapa do convento, Diderot é obrigado a "matá-la", pois 
o marquês de Croismare estava comprando móveis para acolher a freira, tornando a brincadeira dos filósofos muito dispendiosa. Rivette obviamente conhece esta história e decide que a morte da protagonista não vai ser natural: um suicídio (não é de estranhar que o filme tenha causado tanta celeuma com a Igreja, mesmo nos anos 1960, visto que o suicídio é um pecado sem perdão). É uma ruptura radical que quebra com uma série de pressupostos do romance e que, já no início, o filme tinha tratado de uma forma velada e sutil.

Na espécie de "prólogo" do filme, o espectador vê vários gravuras de cenas cotidianas da vida monástica. As telas claras, com as freiras em posições absolutamente simétricas, indicam o regime regrado e harmônico do convento. Porém, uma voz over nos esclarece sobre a vida licenciosa desses lugares, determinando o sentido que devemos dar a essas imagens. Outros quadros, em que o desregramento do comportamento das freiras aparece, confirmam o que acabamos de ouvir. Aparentemente, a sequência se estrutura para denunciar as mazelas da vida corriqueira do claustro. Esta ideia ainda é reforçada porque, depois das gravuras já mencionadas, vemos o retrato de Louise Adèle de Orleans, filha do Regente Philippe, que teria servido de modelo para a superiora lésbica. Ao mostrar esta imagem, estaria Rivette assumindo a piscadela que insinua o conteúdo pornográfico já sugerido no título do romance? Tudo leva a crer que é disso que se trata. O uso da câmera na mão nesta sequência parece confirmar essa ideia, pois faz tremer o plano, desestabilizando a harmonia das representações simétricas do claustro no século XVIII e intensificando a insinuação de licenciosidade dos outros desenhos. De modo que a narrativa que faz alusão às histórias que se leem com uma só mão não aparece apenas nas entrelinhas deste relato.

Por outro lado, quando focaliza o retrato da Louise Adèle, a câmera está fixa e se afasta, num zoom, como fez ao enquadrar a tela de Diderot. A repetição da posição e do movimento da máquina em ambos retratos aproxima os dois personagens, dando à 
freira a mesma importância que se atribui ao filósofo. Assim, em A Religiosa, ou a conotação obscena está no mesmo patamar da filosofia ou a filosofia se encontra irremediavelmente contaminada pela pornografia. Resta ao leitor-espectador decidir. De qualquer forma, o filme nos obriga, sem dúvida, a reler o romance, retirando dele qualquer ranço da moral cristã.

\section{Referências bibliográficas}

APRÁ, Adriano. "La géographie du labyrinthe". In: GIUFRIDDA, Daniela; TOFFETTI, Sergio (Org.). Jacques Rivette: la règle du jeu. Torino: Centre Culturel Français, 1992.

MATTOS, Franklin de. A cadeia secreta. São Paulo: Cosac Naify, 2005. 